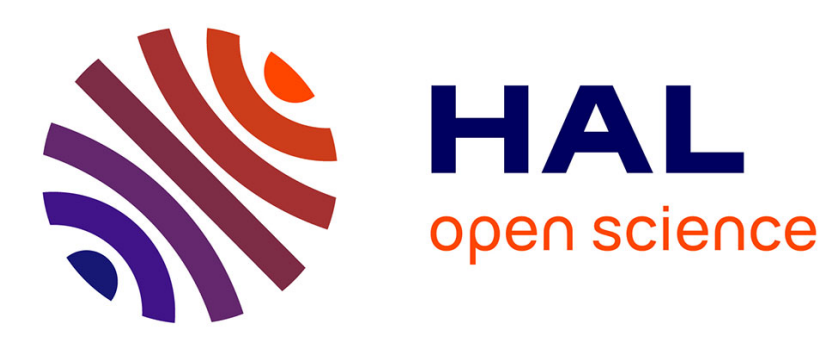

\title{
Bi-Objective Sizing Optimization of a PM Machine Drive on an Operating Profile
}

\author{
Judicael Aubry, Hamid Ben Ahmed, Bernard Multon
}

\section{To cite this version:}

Judicael Aubry, Hamid Ben Ahmed, Bernard Multon. Bi-Objective Sizing Optimization of a PM Machine Drive on an Operating Profile. ICEM 2010, Sep 2010, Rome, Italy. pp.CD-ROM, 10.1109/ICELMACH.2010.5608308 . hal-00516829

\section{HAL Id: hal-00516829 \\ https://hal.science/hal-00516829}

Submitted on 11 Sep 2010

HAL is a multi-disciplinary open access archive for the deposit and dissemination of scientific research documents, whether they are published or not. The documents may come from teaching and research institutions in France or abroad, or from public or private research centers.
L'archive ouverte pluridisciplinaire HAL, est destinée au dépôt et à la diffusion de documents scientifiques de niveau recherche, publiés ou non, émanant des établissements d'enseignement et de recherche français ou étrangers, des laboratoires publics ou privés. 


\title{
Bi-Objective Sizing Optimization of a PM Machine Drive on an Operating Profile
}

\author{
J. Aubry, H. Ben Ahmed, B. Multon
}

\begin{abstract}
This article sets forth a design optimization methodology for an SMPM machine drive on an operating profile. The optimization parameters serve to describe both the machine geometry and electrical ratings of the electronic power converter. Each operating point is treated independently, and current control is optimized at every operating point in order to not only minimize machine drive losses but also satisfy a number of constraints. This optimization methodology will then be applied to the design of a direct-drive conversion chain for a wave energy converter (WEC).
\end{abstract}

Index Terms- Bi-objective optimization, design methodology, direct-drive, operating profiles, optimization methods, particle swarm, permanent-magnet generators, sizing optimization, wave energy conversion.

\section{INTRODUCTION}

$\mathrm{S}$ EVERAL approaches to designing a permanent magnet machine that make use of optimization algorithms, either deterministic [1,2] or stochastic [3,4], have been presented in the literature. Very little research has focused however on such a design exercise over a given operating profile [5]. Yet, for an increasing number of applications (electric traction, renewable energy production, etc.), it proves impossible to define a typical operating point for a given design.

The present article proposes developing a design optimization methodology on the operating profile of an SMPM machine drive for a wave energy conversion application. The term "operating profile" refers herein to a series of torque-speed operating points, denoted $\left(T_{i}, \Omega_{i}\right)$, that the converter-machine set must achieve. All points on the operating profile are taken into account in order to determine objectives and satisfy constraints. The two competing optimization objectives selected in this case are the cost of the electric chain (machine active parts + power electronics) and electrical energy (generated in our case). Both the incorporation and optimization of electronic power converter ratings require adopting a current control strategy (direct and transverse axis current) for each operating point $\left(T_{i}, \Omega_{i}\right)$. This study will examine two contributions of flux weakening for permanent magnet machine drives:

- Extension of the constant power speed range. In several articles [6-11], it is shown that electronic flux weakening (through modification of the leading angle or injection of a demagnetizing direct axis current) makes it possible, for

This work was supported by the Bretagne regional council under Grant ARED SEAREV 2.

J. Aubry is with SATIE, ENS Cachan Bretagne, CNRS, UEB, av Robert Schuman, F-35170 BRUZ (e-mail: judicael.aubry@bretagne.ens-cachan.fr).

A. H. Ben Ahmed is with SATIE, ENS Cachan Bretagne, CNRS, UEB, av Robert Schuman, F-35170 BRUZ (e-mail: benahmed@bretagne.enscachan.fr).

B. Multon is with SATIE, ENS Cachan Bretagne, CNRS, UEB, av Robert Schuman, F-35170 BRUZ (e-mail: bernard.multon@bretagne.enscachan.fr). given converter ratings, to extend the operating speed range of a machine drive with respect to a conventional control (e.g. an $i_{d}=0$ control).

- Minimization of losses [12-14]. By restricting losses to just copper losses, then loss minimization at each operating point necessitates a so-called "maximum torque per ampere" control, which within the scope of non-salient machines, may be expressed very simply as $i_{d}=0$. By adding other losses (magnetic, converter) to this formulation, the control law for minimizing losses at each point becomes more complex, while still remaining feasible.

A broad array of research has been conducted to take advantage of these two contributions from flux weakening. Yet such research has been limited to optimizing only the control strategy [15], or optimizing the control and machine geometry (excluding the converter) [16], or lastly optimizing the control-converter-machine set while focusing on just a single criterion (either the machine mass [17] or losses on the operating profile [18]).

The first part of this paper will discuss the general optimization problem associated with the design of a machine drive; this will entail presenting the two selected competing objectives in addition to the set of machine drive design parameters and relevant constraints. The second part will demonstrate how to optimize the direct axis current $i_{d}$ in order to minimize a loss criterion for each operating point, with respect to both converter design parameters and magnet demagnetization. Afterwards, the models used to perform this optimization routine will be described in detail. The last part will apply the approach developed to the study of a pendulum system devoted to wave energy conversion.

\section{PRESENTATION OF The OPtimization PROBLEM}

\section{A. Optimization objectives}

From a classical perspective, the design objectives for a machine drive could consist of machine mass, machine cost or total losses. Two specific and competing objectives will be discussed here: total cost of the machine drive, and electrical energy.

\section{1) Objective 1: Cost of the electric chain}

In order to evaluate the machine drive cost, we consider the sum of the power electronics cost (inverter, filters, control circuits) and machine cost, e.g.:

$$
C_{\text {drive }}=C_{\text {conv }}+C_{\text {mach }}
$$

Our assumption is that the cost of the converter is a function of its apparent power (2) (stemming from observation). As for the machine cost, only the sum of costs for raw materials and active parts have been taken into account (3), with numerical values being listed in Table II.

$$
C_{\text {conv }}=\alpha S_{\text {conv }}^{\beta}
$$




$$
C_{\text {mach }}=c_{N d F e B} V_{N d F e B}+c_{F e} V_{F e}+c_{C u} V_{C u}
$$

Coefficients $\alpha$ and $\beta$ may be adjusted depending on the application (large or small series), and they remain valid for a given power range and conversion structure. The coefficients for an IGBT three-phase bridge will be provided in the application example further below.

\section{2) Objective 2: Electrical energy}

Depending on the specific application, e.g. whether motor or generator, the electrical energy may be either consumed or generated. If we adopt a motor convention, in both cases this electrical energy requires minimization:

$$
E_{\text {elec }}=\sum_{i}\left(T_{i} \Omega_{i}+P_{\text {loss }, i}\right) d_{i}
$$

where $P_{\text {loss }, i}$ are the total machine drive losses at operating point $\left(T_{i}, \Omega_{i}\right)$ with a duration of $d_{i}$.

\section{B. Optimization parameters}

The target to be optimized is an SMPM machine drive. The optimization parameters thus need to describe the two physical components making up this system : machine and converter.

Let's assume the DC bus voltage $U_{D C}$ to be constant. The converter will then be parameterized by its rated current $\left(I_{\text {rated }}\right.$ with $S_{\text {conv }}=3 V_{\text {rated }} I_{\text {rated }}$ and $\left.V_{\text {rated }}=U_{D C} / 2 \sqrt{2}\right)$.

In order to effectively describe the machine, let's identify just the geometric parameters shown in Fig. 1 and listed in Table I below.

TABLE I

OPTIMIZATION PARAMETERS

\begin{tabular}{ll}
\hline \hline Symbol & \multicolumn{1}{c}{ Description } \\
\hline$I_{\text {rated }}$ & Rated current of the power electronic converter (A) \\
\hline$e$ & Airgap length (m) \\
$h_{\text {mag }}$ & Magnet height (m) \\
$h_{\text {rot }}$ & Rotor yoke height (m) \\
$h_{\text {slot }}$ & Slot height (m) \\
$h_{\text {stat }}$ & Stator yoke height (m) \\
$k_{c f}$ & Copper-to-iron ratio in the slotting area (-) \\
$l_{u}$ & Active machine length (m) \\
$p$ & Number of pole pairs (-) \\
$r_{s}$ & Inner stator radius (m) \\
$n_{s}$ & Number of turns in series per phase \\
\hline
\end{tabular}

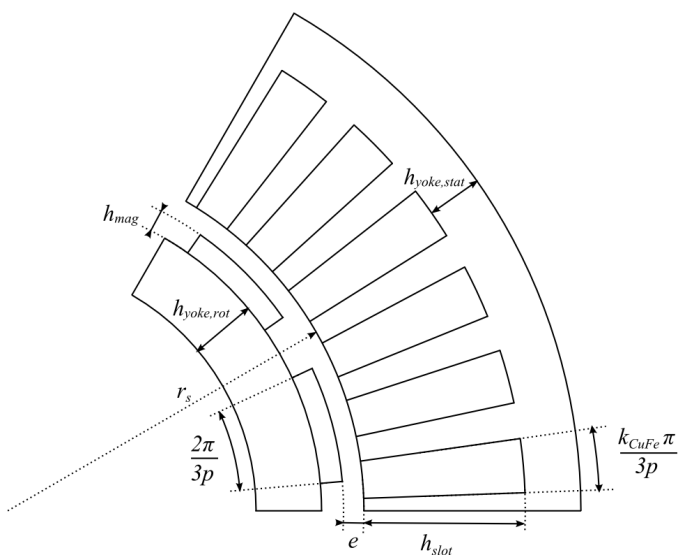

Fig. 1: Geometric parameterization of the PM machine

\section{Optimization constraints}

To complete the description of this optimization problem, several constraints still need to be defined.

Some constraints must be satisfied at each operating point $\left(T_{i}, \Omega_{i}\right)$ :

$$
\begin{array}{llll}
\text { - } & \text { Rated voltage: } & \forall i \quad V_{i} \leq V_{\text {rated }} \\
\text { - } & \text { Rated current: } & \forall i \quad I_{i} \leq I_{\text {rated }} \\
\text { - } & \text { Saturation: } & \forall i \quad \max \left(B_{i}\right) \leq 1,5 T \\
\text { - } & \text { Demagnetization: } & \forall i \quad H_{i} \geq-H_{k}
\end{array}
$$

Other geometrical constraints however must be satisfied for each machine drive, e.g.:

$$
\begin{array}{ll}
- & e>0.2+3 \sqrt{r_{s} l_{s}}(\mathrm{~mm}) \\
- & r_{s}+h_{\text {slot }}+h_{\text {stat }} \leq r_{\max } \\
- & r_{s}-e \geq h_{\text {rot }}
\end{array}
$$

The thermal constraint must be treated with special attention. The temperature rise relative to ambient temperature must be calculated strictly by means of a transient thermal model. The maximum value over the entire increasing temperature profile must therefore remain below a threshold value : $\max (\Delta \Theta(t))<\Delta \Theta_{\max }$

Should the sequencing of operating points not be known, only one thermal model in the steady-state mode may be used and the temperature rise for each operating point is denoted $\Delta \Theta_{i}$. Two scenarios then become possible:

- When thermal time constants of the machine are large relative to the loss variation periods, the temperature rise constraint can be calculated based on average loss value : $\operatorname{mean}\left(\Delta \Theta_{i}\right)<\Delta \Theta_{\max }$

- When the thermal time constants are small relative to the loss variation periods, temperature rise may be considered as instantaneous and the corresponding constraint appears on the least favorable operating point : $\max \left(\Delta \Theta_{i}\right)<\Delta \Theta_{\max }$

Depending on the application and level of power under consideration, one of these two scenarios may be envisaged.

Otherwise, it would be necessary to calculate the temperature rise profile on the basis of a transient thermal model, which could cause a higher computation time.

\section{CURRENT CONTROL OPTIMIZATION ON AN OPERATING POINT}

In order to evaluate machine drive losses $P_{\text {loss }, i}$ at operating point $\left(T_{i}, \Omega_{i}\right)$, the direct axis current $i_{d, i}$ still needs to be determined. The transverse axis current $i_{q, i}$, in case of a non-salient machine, is defined by the torque $T_{i}$ to be supplied.

The values of currents $i_{d, i}$ at each operating point should constitute strictly optimization parameters to the same extent as machine drive design parameters. On an operating profile containing a large number of points however, this rigorous approach is infeasible since it leads to an excessive increase in the number of optimization parameters.

The alternative approach adopted herein consists of locally optimizing the value of current $i_{d, i}$ for each operating point. Let's assign the minimization of total machine drive losses $P_{\text {loss }}$ as the optimization criterion, which in turn contributes to optimizing one of the two design objectives, namely electrical energy $E_{\text {elec }}$.

As indicated in the previous section however, some constraints must be satisfied at each operating point $\left(T_{i}, \Omega_{i}\right)$ : voltage, current, saturation and demagnetization. The value 
$i_{d, i}$ must therefore be optimized subject to these constraints. Should no optimization solution exist, e.g. no $i_{d, i}$ value found to satisfy all four constraints, then the particular operating point cannot be reached. An illustration of this optimization protocol is presented in Fig. 2 (only voltage and current constraints are illustrated).

A new constraint will now be defined that encompasses the four mentioned above: each operating point $\left(T_{i}, \Omega_{i}\right)$ must be reached.

In practice, this constrained optimization routine is performed by systematically computing several discrete values lying within the interval $\left[-I_{\text {rated }} ; 0\right]$. The selected $i_{d, i}$ value is the one that minimizes losses while satisfying constraints. The number of computed discrete values will be established on the basis of a compromise between level of accuracy and computation time.

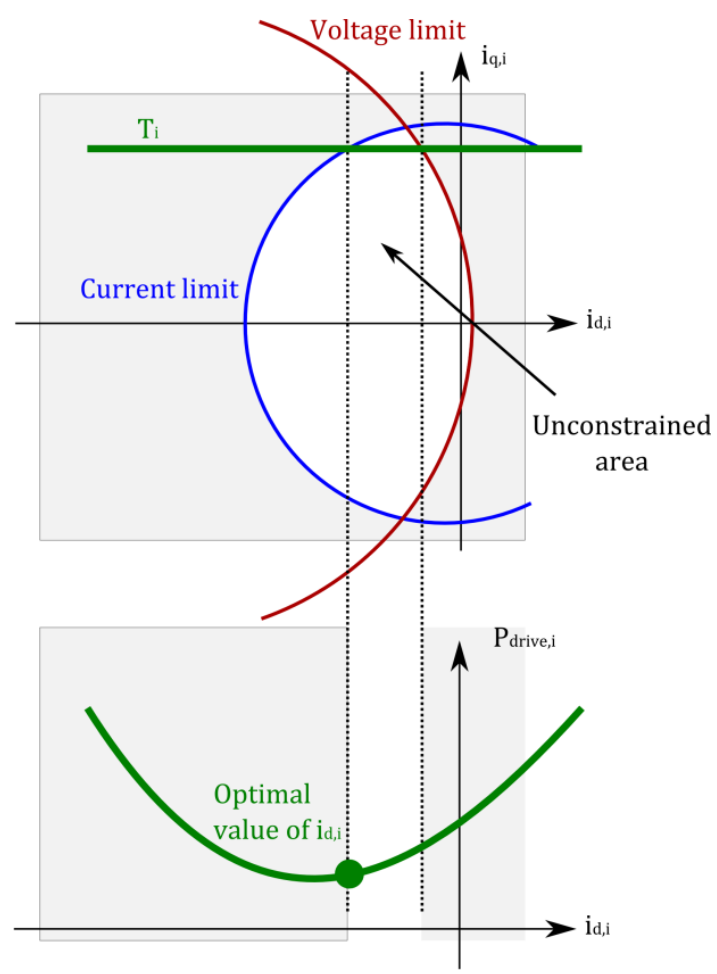

Fig. 2: Constrained optimization of $\boldsymbol{i}_{\boldsymbol{d}, \boldsymbol{i}}$ for minimizing $\boldsymbol{P}_{\text {drive }, \boldsymbol{i}}$

If converter losses are not included in the local optimization objective, a simple analytical expression can be derived for the constrained optimal current. This internal optimization loop can then be more quickly processed numerically.

\section{MACHINE DRIVE MODELIZATION}

The goal of this modeling effort is to determine the objectives to be optimized based on a set of optimization parameters. The "economical cost" objective does not require any kind of physical model, but the electrical energy calculation requires knowing the losses at each operating point.

This modelization is restricted to the first harmonic and decomposes airgap induction on two axes that rotate synchronously with the electrical angular velocity $\omega(\mathrm{d}-\mathrm{q}$ axes). The hypotheses adopted to build this model consist of: infinite iron permeability, and the independence of electrical quantities with respect to temperature.

\section{A. Electrical machine model}

The equivalent circuits in both axes are depicted in Fig. 3. The iron loss resistance $R_{f}$ is neglected during the calculation of electrical values.

The decomposition into $d-q$ axis has been chosen so that the RMS current value per phase and the RMS phase to neutral voltage are both expressed as follows:

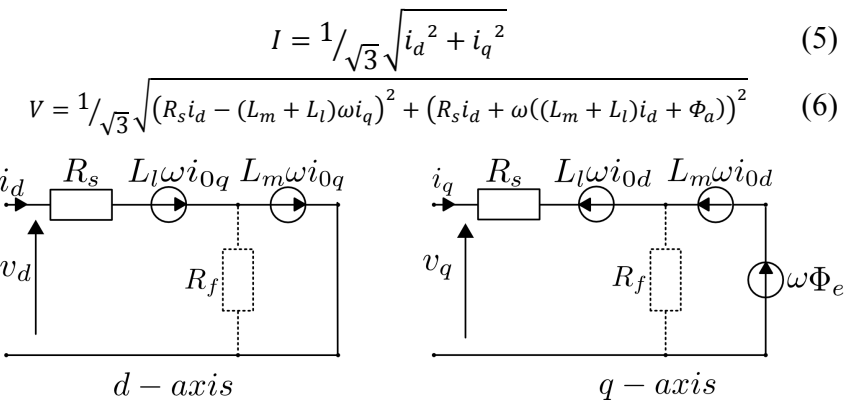

Fig. 3: $d$ - and $q$-equivalent circuits of the SMPM machine

$R_{s}$ : $\quad$ Armature winding resistance per phase

$R_{f}$ : $\quad$ Equivalent iron loss resistance

$\Phi_{f}: \quad \sqrt{3} \Phi$

$\Phi_{e}$ : $\quad$ Flux linkage of the PM per phase (r.m.s. value)

$L_{m}$ : Magnetizing inductance

$L_{l}$ : $\quad$ Leakage inductance

The electromagnetic torque equals:

$$
T=p \Phi_{e} i_{q}
$$

\section{B. Model of machine drive losses}

The resistance $R_{s}$ of one phase is determined from the set of geometric parameters. Copper resistivity is set at the maximum allowable temperature. The dependence of resistivity or other physical quantities on temperature could be incorporated by means of an iterative calculation, yet computation time would rise excessively.

$$
P_{\text {copper }, i}=R_{s}\left(i_{d, i}^{2}+i_{q, i}^{2}\right)
$$

Iron losses are calculated in the first harmonic hypothesis. The consideration of harmonic losses in the model would not cause any additional difficulties. Equation (9) is used to calculate loss densities:

$$
\begin{aligned}
p_{\text {iron }, i} & =p_{\text {hyst }, i}+p_{\text {eddy }, i} \\
& =\frac{2 k_{H}}{\pi}\left|\Omega_{i}\right| \widehat{B}_{\imath}^{2}+\alpha_{p} \frac{\left(p \Omega_{i} \widehat{B}_{l}\right)^{2}}{2}
\end{aligned}
$$

Total iron losses are derived from (9) by summing total losses in both the teeth and stator yoke. Loss densities are considered to be homogeneous in each of these two parts (rotor losses are assumed to equal zero for this model in the first harmonic under steady-state mode).

Losses in the electronic power converter are composed of the sum of conduction losses (10) and switching losses (13) within both the diodes and transistors (in this case IGBT).

$$
P_{\text {cond }}=V_{0, x} I_{\text {moy }, x}+R_{d, x} I_{r m s, x}^{2}
$$

where $x$ is the component under consideration (diode or IGBT), $V_{0, x}$ the threshold voltage of the component and $R_{d, x}$ its dynamic resistance. Observations gleaned from manufacturers' documentation enable deducing, for a given 
maximum voltage rating, the scale law as a function of the maximum current rating of the various components:

$$
\begin{aligned}
& V_{0, x}=v_{x} /\left(\sqrt{2} I_{\text {rated }}\right) \\
& R_{d, x}=r_{x} /\left(\sqrt{2} I_{\text {rated }}\right)
\end{aligned}
$$

Switching losses are assumed to be proportional to the switched current:

$$
P_{s w}=f_{s w}\left(B_{s w}+B_{r e c}\right) I_{r m s} \sqrt{2} / \pi
$$

where $B_{s w}$ and $B_{r e c}$ are the switching loss coefficients in the IGBT and diode, respectively. The hypothesis will be adopted whereby for a given maximum voltage rating, these coefficients remain independent of the maximum current rating of the switches.

\section{Magnetic machine model}

An expression of the magnetizing inductance $L_{m}$ is shown in (14) for a diametral winding with one slot per pole and per phase:

$$
L_{m}=\frac{3}{2} \frac{4}{\pi} \frac{\mu_{0}}{K_{c} e+h_{a}} n^{2} r_{s} l_{u} p^{2}
$$

where $K_{c}$ is Carter's coefficient [19].

The leakage inductance $L_{l}$ is obtained from a calculation of the magnetic energy stored in a single slot (end windings and tooth tips have been neglected herein), which yields:

$$
L_{l}=2 \mu_{0} \frac{n^{2} l_{s}}{p^{2}} \frac{h_{\text {slot }}}{3 w_{\text {slot }}}
$$

\section{Thermal machine model}

The equivalent thermal circuit of the machine is displayed in Fig. 4. Due to symmetry considerations, only half of a tooth pitch has been examined.

To begin, the curvature effects are neglected and losses are distributed; in this case, the calculation of equivalent circuit elements requires special attention [20]. The expression for thermal resistances is detailed for the slot only as follows:

$$
\begin{aligned}
R_{t h \_s l o t, r a d} & =\frac{1}{\lambda_{C u}} \frac{h_{s}}{l_{u} w_{s} / 2} \\
R_{t h \_s l o t, t g} & =\frac{1}{\lambda_{C u}} \frac{w_{s} / 2}{l_{u} h_{s}}
\end{aligned}
$$

$P_{C u, s l o t}$ corresponds to the copper loss produced inside a half-slot.

$\lambda_{C u}$ corresponds to the equivalent thermal conductivity of the stator winding (copper + insulation), set equal to $0,5 \mathrm{~W} \cdot \mathrm{m}^{-1} \cdot \mathrm{K}^{-1}$ in the case of vacuum impregnation.

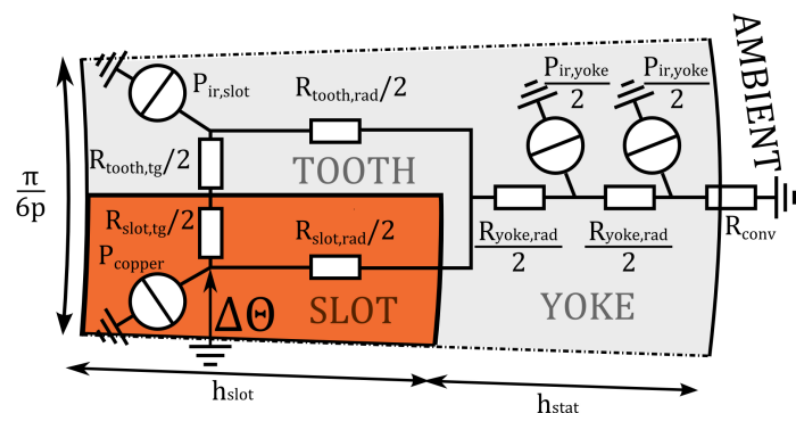

Fig. 4: Equivalent thermal circuit of the PM machine
The resistances $R_{\text {slot,tg }}$ and $R_{\text {tooth,tg }}$ enable incorporating the tangential heat flux from the slot to the tooth; this flux cannot be neglected in the case where slot depth is greater than slot width.

The resistance $R_{\text {conv }}$ serves to model the thermal exchange taking place by convection and radiation.

The value of the temperature rise constraint $\Delta \Theta$ is calculated inside the winding; it corresponds to the temperature gain between the hottest point of the slot and the ambient temperature.

For the sake of simplification, a thermal model of the electronic power converter was not developed since maximum current ratings have been established on the basis of manufacturer guidelines; moreover, it can be considered that cooling will be adapted in order to maintain the junction temperature at an acceptable value.

\section{DESIGN OPTIMIZATION ON AN OPERATING PROFILE}

This article has demonstrated how to evaluate and optimize the performance of a given machine drive at an operating point. Fig. 5 offers the optimization flowchart. The cost of the electric chain, along with the geometric constraints, may be directly assessed from the parameters presented. Electrical energy and the thermal constraint are calculated from losses. If for a given operating point no solution exists that optimizes $i_{d, i}$, then the corresponding set of optimization parameters will not be selected as part of the overall design optimization.

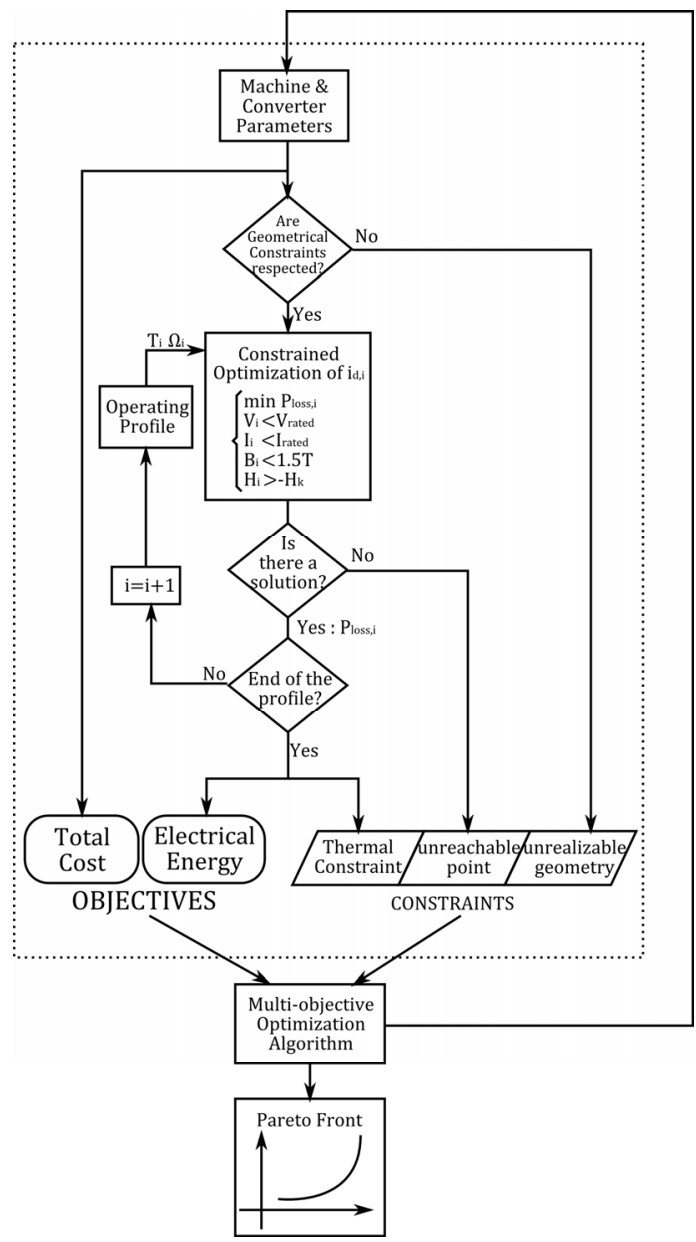

Fig. 5: Operating cycle design - The optimization flowchart 


\section{A. Bi-objective optimization algorithm}

We introduced a bi-objective optimization algorithm, based on both Particle Swarm Optimization (PSO) and Pareto Dominance [21], in order to complete the overall design optimization loop. This algorithm has been implemented in a Matlab environment; the weighting factor was set at 0.7 , and the social learning factor and cognitive learning factor both at 1 . Leaders were selected from an elitist archive. A crowding factor was used to limit its size to 200.

The leader choice strategy is described in Fig. 6. All of the swarm was evenly spread across the archive so as to assign a leader to each particle. The first particles of the swarm thus always minimize the first objective, while the last particles optimize the second objective.

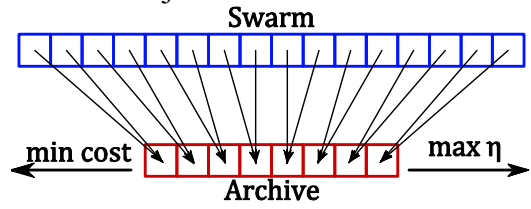

Fig. 6: Leader choice strategy for the considered MOPSO algorithm

The size of the swarm has been set at 2,000, and 500 generations were chosen. Total computation time lasted roughly $1,000 \mathrm{~s}$ on a quad-core $\mathrm{PC}$. To ensure good convergence, the algorithm was run 10 times. The results discussed below represent a combination of the results from each run.

\section{B. Application: Optimization of an all-electric conversion chain for a wave energy converter}

SEAREV (French acronym for Autonomous Electrical System of Wave Energy Conversion) is a wave energy conversion system $[22,23]$ composed of a float actuated by swell movement. Inside this device, an eccentric mass wheel oscillates relative to the float. An electric generator operating in direct drive converts the mechanical energy of the pendular wheel into electrical energy, thereby causing damping of the relative motion between these two parts. One strategy for controlling the conversion torque consists of generating, via the associated machine drive, a viscous friction torque, e.g. introducing a resistant torque proportional to the angular velocity in addition to a leveling of the converted mechanical power. For each operating point, torque $T_{i}$ can thus be correlated with angular velocity $\Omega_{i}$ by (18).

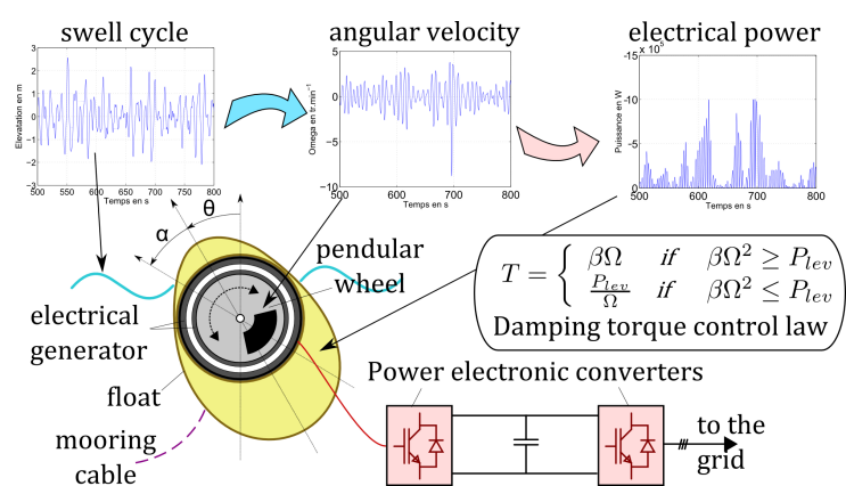

Fig. 7: Schematic diagram of the SEAREV WEC operating principle

$$
T_{i}=\left\{\begin{array}{l}
\beta \Omega_{i} \text { if } \beta \Omega_{i}^{2}>P_{l e v} \\
\frac{P_{l e v}}{\Omega_{i}} \text { if } \beta \Omega_{i}^{2} \leq P_{l e v}
\end{array}\right.
$$

The operating profile considered in this work was obtained for a viscous damping coefficient $\beta$ equal to $-5.10^{6} \mathrm{~N} . \mathrm{m} . \mathrm{s}^{-1}$ and a clipping power $P_{l e v}$ of $-1 \mathrm{MW}$, both having been optimized for the state of an ocean swell $\left(H_{s}=3 m, T_{p}=8 s\right)$. This temporal angular velocity and torque profiles are depicted in Fig. 8. The time step was set at $0.1 \mathrm{~s}$ with a total cycle duration of $1,200 \mathrm{~s}$. The total number of operating points thus equals 12,000 . In order to reduce the number of points to be calculated, speed values were discretized and the probability of occurrence for each of the resulting discrete values was then calculated. Fig. 9 shows the simplified cycle placed within the torque-speed plane. The area of each plotted point is proportional to the probability of appearance times the mechanical power $\left(T_{i} \Omega_{\mathrm{i}} d_{i} / \sum_{i} d_{i}\right)$

TABLE II

PROBLEM CONSTANTS

\begin{tabular}{|c|c|c|}
\hline Symbol & Description & Value \\
\hline$B_{r}$ & Remanent induction & $1 T$ \\
\hline$k_{\text {fill }}$ & Slot-filling coefficient & 0.4 \\
\hline$k_{H}$ & Hysteresis loss coefficient & $90 A \cdot m(V \cdot s)^{-1}$ \\
\hline$\alpha_{p}$ & Eddy current loss coefficient & 0.065 A.m. $V^{-1}$ \\
\hline$\rho_{C u}$ & Copper resistivity & $2.5 \cdot 10^{-8} \Omega . m^{-1}$ \\
\hline$h$ & Convection coefficient & $10 W \cdot m^{-2} \cdot K^{-1}$ \\
\hline$\lambda_{C u}$ & $\begin{array}{l}\text { Equivalent thermal conductivity of } \\
\text { the winding }\end{array}$ & $0.5 W(m \cdot K)^{-1}$ \\
\hline$\lambda_{F e}$ & Radial iron thermal conductivity & $30 W(m \cdot K)^{-1}$ \\
\hline$f_{s w}$ & Switching frequency & $2 \mathrm{kHz}$ \\
\hline$v_{I G B T}$ & Bias voltage for IGBT (diode) per & $2341 V \cdot A^{-1}$ \\
\hline$v_{\text {diode }}$ & ampere-rating & $1800 V . A^{-1}$ \\
\hline$r_{I G B T}$ & Dynamic resistance for IGBT & $1500 \mathrm{~m} \Omega \cdot A^{-1}$ \\
\hline$r_{\text {diode }}$ & (diode) per ampere-rating & $1200 \mathrm{~m} \Omega . A^{-1}$ \\
\hline $\begin{array}{l}B_{s w} \\
+B_{r e c}\end{array}$ & Switching loss coefficient & $3 m J \cdot A^{-1}$ \\
\hline \multicolumn{3}{|c|}{ COST PARAMETERS } \\
\hline$\alpha$ & Converter cost coefficient (viable & 3.3 \\
\hline$\beta$ & for a three-phase IGBT bridge) & 0.7 \\
\hline$c_{N d F e B}$ & Magnet cost & $30(€ / k g)$ \\
\hline$c_{F e}$ & Lamination cost & $3(€ / k g)$ \\
\hline$c_{C u}$ & Copper cost & $6(€ / k g)$ \\
\hline \multicolumn{3}{|c|}{ CONSTRAINT PARAMETERS } \\
\hline$U_{D C}$ & DC bus voltage & $1300 \mathrm{~V}$ \\
\hline$e_{\min }$ & Minimum feasible airgap ( $\mathrm{mm}$ ) & $0.2+3 \sqrt{r_{s} l_{s}}$ \\
\hline$r_{\text {ext } \max }$ & Maximum outer stator radius & $5 m$ \\
\hline$B_{\text {sat }}$ & Maximum induction level & $1.5 T$ \\
\hline$H_{k}$ & Magnet coercivity & $-760 \cdot 10^{3} A \cdot m^{-1}$ \\
\hline$\Delta \Theta_{\max }$ & Maximum temperature rise & $110 \mathrm{~K}$ \\
\hline
\end{tabular}

The SEAREV system therefore provides an application example of this optimization method on a cycle running in energy generation mode. The level of power being considered allows adopting the hypothesis previously described on transient thermal states, with the temperature rise constraint then being calculated on the basis of the average value of copper and iron losses. Only the converter on the machine side has been included in this example when 
calculating costs and losses. The scale law coefficients on the power electronic components were derived for a maximum voltage rating of $3,300 \mathrm{~V}$.

In this example, the direct axis current is optimized at each operating point in order to minimize total machine drive losses. The numerical method employed to perform this constrained optimization has been described in the section III. The number of discrete values tested for $i_{d}$ has been fixed at 100 within the interval $\left[-I_{\text {rated }} ; 0\right]$.
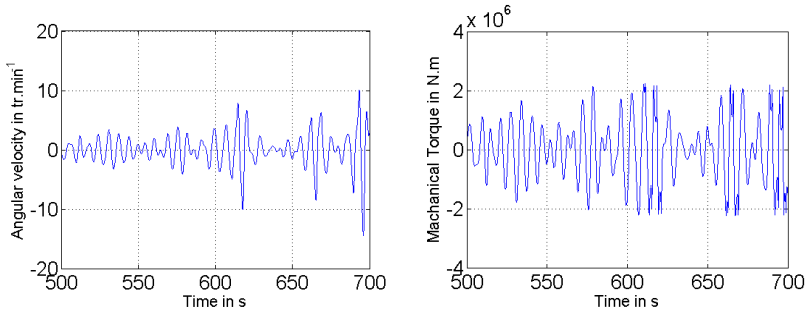

Fig. 8: Operating profiles (angular velocity and torque) vs. time -

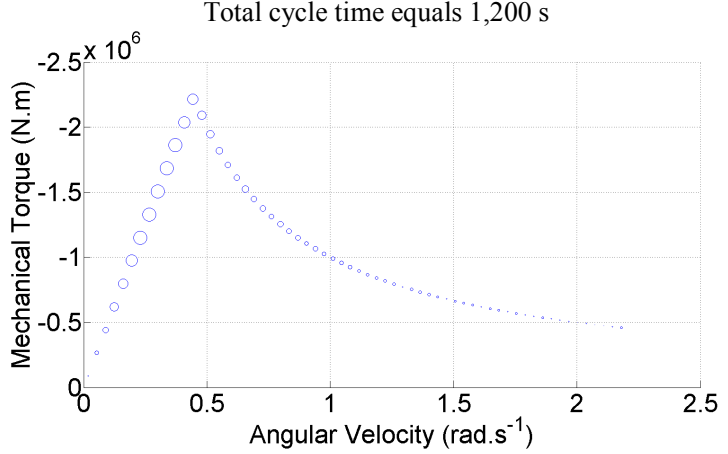

Fig. 9: Simplified operating profile in the $(C, \Omega)$ plane - The area of each point is proportional to its mechanical energy potential (e.g. frequency of appearance * mechanical power)

The optimization results are presented in Fig. 11 and 12. The Pareto front indicates the set of best solutions relative to both the electric chain cost $C_{\text {drive }}$ and average electric power $P_{\text {average }}$, which is a reflection of the produced electrical energy (e.g. the mechanical power (negative) at which the sum of losses (positive) was added). The distribution of losses and costs for the four specific solutions is displayed in Fig. 12. The parameters of these four solutions are then detailed in Table III, and Fig 10 shows the operating area capable of being reached by Solution A along with the simplified operating profile. The shading indicates the optimized constrained leading angle (in generator mode $\left.\Psi_{\mathrm{i}}=\pi-\tan ^{-1}\left(i_{d, i} / i_{q, i}\right)\right)$ at each operating point for the purpose of minimizing machine drive losses.

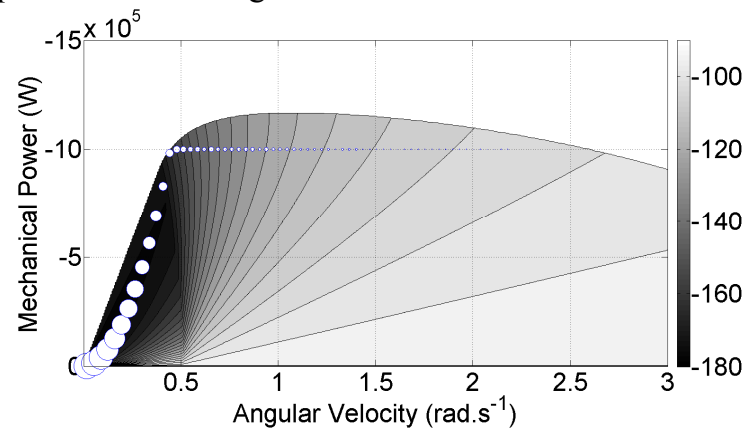

Fig. 10: Contour plot of the optimized leading angle $\boldsymbol{\Psi}$ in degrees in the $(\mathrm{P}, \Omega)$ plane for the solution $\mathrm{A}$ - Here, the area of each point is proportional to its frequency of appearance

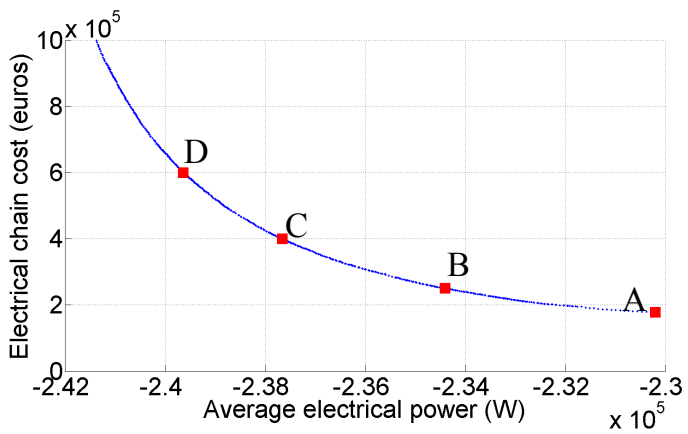

Fig. 11: Pareto front for these optimization results

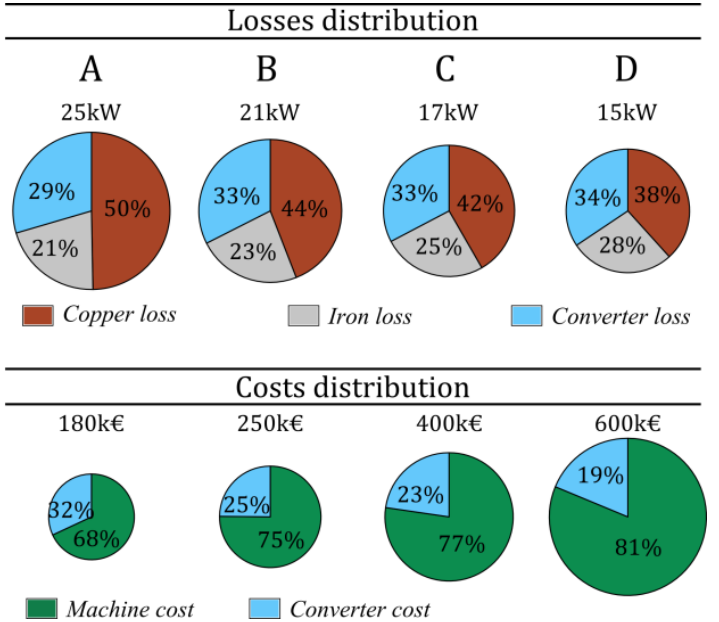

Fig. 12: Distribution of losses and costs for four specific solutions

TABLE III

FOUR DETAILED SOLUTIONS OF THE PARETO FRONT

\begin{tabular}{ccccc}
\hline & $\mathrm{A}$ & $\mathrm{B}$ & $\mathrm{C}$ & $\mathrm{D}$ \\
\hline$P_{\text {average }}$ & $-230 \mathrm{~kW}$ & $-234 \mathrm{~kW}$ & $-238 \mathrm{~kW}$ & $-240 \mathrm{~kW}$ \\
$C_{\text {drive }}$ & $180 \mathrm{k \epsilon}$ & $250 \mathrm{k} €$ & $400 \mathrm{k \epsilon}$ & $600 \mathrm{k}$ \\
\hline$S_{\text {conv }}$ & $1.1 \mathrm{MVA}$ & $1.3 \mathrm{MVA}$ & $2.1 \mathrm{MVA}$ & $2.9 \mathrm{MVA}$ \\
$e$ & $5.1 \mathrm{~mm}$ & $4.8 \mathrm{~mm}$ & $5.4 \mathrm{~mm}$ & $5.9 \mathrm{~mm}$ \\
$h_{\text {mag }}$ & $11 \mathrm{~mm}$ & $15 \mathrm{~mm}$ & $18 \mathrm{~mm}$ & $20 \mathrm{~mm}$ \\
$h_{\text {rot }}$ & $3 \mathrm{~cm}$ & $4 \mathrm{~cm}$ & $7 \mathrm{~cm}$ & $9 \mathrm{~cm}$ \\
$h_{\text {slot }}$ & $18 \mathrm{~cm}$ & $28 \mathrm{~cm}$ & $35 \mathrm{~cm}$ & $42 \mathrm{~cm}$ \\
$h_{\text {stat }}$ & $3 \mathrm{~cm}$ & $6 \mathrm{~cm}$ & $10 \mathrm{~cm}$ & $16 \mathrm{~cm}$ \\
$k_{c f}$ & $56 \%$ & $51 \%$ & $52 \%$ & $55 \%$ \\
$p$ & 126 & 80 & 51 & 36 \\
$l_{u}$ & $55 \mathrm{~cm}$ & $51 \mathrm{~cm}$ & $65 \mathrm{~cm}$ & $82 \mathrm{~cm}$ \\
$r_{s}$ & $4.8 \mathrm{~m}$ & $4.6 \mathrm{~m}$ & $4.5 \mathrm{~m}$ & $4.4 \mathrm{~m}$ \\
$n_{s}$ & 378 & 400 & 357 & 342 \\
\hline$M_{\text {machine }}$ & $25 \mathrm{t}$ & $41 \mathrm{t}$ & $70 \mathrm{t}$ & $110 \mathrm{t}$ \\
$L_{m}$ & $3.3 \mathrm{mH}$ & $6.4 \mathrm{mH}$ & $13 \mathrm{mH}$ & $22 \mathrm{mH}$ \\
$L_{l}$ & $4 \mathrm{mH}$ & $7.5 \mathrm{mH}$ & $9.2 \mathrm{mH}$ & $11 \mathrm{mH}$ \\
$R_{s}$ & $24 \mathrm{~m} \Omega$ & $20 \mathrm{~m} \Omega$ & $17 \mathrm{~m} \Omega$ & $15 \mathrm{~m} \Omega$ \\
$\Phi_{e}$ & $7 \mathrm{~Wb}$ & $12 \mathrm{~Wb}$ & $21 \mathrm{~Wb}$ & $31 \mathrm{~Wb}$ \\
\hline & & & &
\end{tabular}

\section{CONCLUSION}

This paper has presented a machine drive optimization methodology applied on an operating profile with a strong coupling between the machine and the power electronic converter. The aim was optimizing the design of an allelectric conversion chain for a wave energy conversion system. This methodology proves to be applicable to any system in which a machine drive is operating at variable 
speed, like for electric traction or renewable energy conversion.

A number of simplifying hypotheses were adopted, primarily to save computation time, yet the integration of more complex models would not pose a problem from a methodological standpoint. A machine model based on finite elements could even be used to more accurately calculate magnetic losses, particularly under conditions of considerable flux weakening, although computation time would rise substantially. A transient thermal model could also improve quality of results especially for applications where thermal time constants of the machine are near from the loss variation periods.

\section{REFERENCES}

[1] G. R. Slemon, X. Liu "Modeling and Design Optimization of Permanent Magnet Motors", Electric Machines and Power Systems, Vol. 20, pp. 71-92, 1992.

[2] F. Messine, B. Nogarede, J.L. Lagouanelle, "Optimal Design of Electromechanical Actuators: A New Method Based on Global Optimization", IEEE Trans. on Mag., Vol. 34, No. 1, Jan. 1998.

[3] N. Bianchi, S. Bolognani "Design optimization of electric motor by genetic algorithms", IEE Proc. Electr. Power Appl., Vol. 145, No. 5, Sept. 1998

[4] N. Boules "Design Optimization of Permanent Magnet DC Motors", IEEE Trans. On Ind. Appl., Vol. 26, No. 4, Jul-Aug 1990.

[5] F. Biais and P. Langry, "Optimization of a permanent magnet traction motor for electric vehicle", EVS 15, Bruxelles, Oct 1998

[6] T.M. Jahns, "Flux-Weakening Regime Operation of an Interior Permanent-Magnet Synchronous Motor Drive", IEEE Trans. on Ind. Appl., Vol. 23, No. 4, pp. 681-689, Jul-Aug 1987.

[7] B. Sneyers, W. Novotny, T.A. Lipo, "Field Weakening in buried Permanent Magnet AC Motor Drives", IEEE Trans. on Ind. Appl., Vol. 21, No. 2, pp. 398-407, Mar-Apr 1985.

[8] W.L. Soong, T.J.E. Miller, "Field-weakening performance of brushless synchronous AC motor drives", IEE Proc.- Electr. Power Appl., Vol. 141, No. 6, pp. 331-340, Nov. 1994.

[9] S. Morimoto, Y. Takeda, T. Hirisa, K. Taniguchi, "Expansion of operating limits for permanent magnet motor by current vector control considering inverter capacity", IEEE Trans. Ind. Appl., Vol. 26, No. 5 , pp. 866-871, Sep/Oct 1990.

[10] T. Sebastian, G.R. Slemon, "Operating Limits of Inverter-Driven Permanent Magnet Motor Drives", IEEE Trans. on Ind. Appl., Vol. 23, No. 2, pp. 327-333, Mar-Apr 1987.

[11] B. Multon, J. Lucidarme, L. Prévond, "Analyse des possibilités de fonctionnement en régime de désexcitation des moteurs à aimants permanents", J. Phys. III France, No. 5, pp. 623-640, May 1995.

[12] C. Mademlis, J. Xypteras, N. Margaris, "Loss minimization in surface permanent magnet synchronous motors drives", IEEE Trans. Ind. Appl., Vol. 47, No. 1, pp. 115-122, Feb. 2000.

[13] F. Fernandez-Bernal, A.R. Garcia-Cerrada Faure, "Model-based loss minimization for DC and AC vector-controlled motors including core saturation", IEEE Trans. Ind. Appl., Vol. 36 , No. 3, pp. 755-763, May-June 2000.

[14] S. Morimoto, Y. Tong, Y. Takeda, T. Hirisa, "Loss minimization control of permanent magnet synchronous motors drives," IEEE Trans. Ind. Electron., Vol. 41, No. 5, pp. 511-517, Oct. 1994.

[15] L. Chédot, G. Friedrich, "Comparison of direct and adaptative optimal controls for interior permanent magnet synchronous integrated starter generator", IEEE International Electrical Machine and Drive Conference (IEMDC 03), Madison, Wisconsin, USA, June 2003.
[16] O. de la Barrière, S. Hlioui, H. Ben Ahmed, M. Gabsi, M. LoBue, "PM Axial Flux Machine Design for hybrid Traction", Oil \& Gas Science and Technology, 2009, DOI: 10.2516/ogst/2009058.

[17] S. Kreuawan, "Modeling and optimal design for railway applications" (in French: "Modélisation et conception optimal pour les application ferroviaires"), Ph.D. thesis, Ecole Centrale de Lille, France, 24 Nov 2008.

[18] J.R. Figueroa Barnier, "Wide speed range drive modeling for design purposes" (in French: "Modélisation des entraînements à grande plage de vitesse en vue de leur conception"), Ph.D. thesis, Laval University, Quebec, 2008.

[19] J. Gieras, M. Wing, "Permanent magnet motor technology: Design and application", CRC Press, 2002.

[20] D. Gerling, G. Dajaku, "Novel lumped-parameter thermal model for electrical systems", in Proc. EPE 2005, Dresden.

[21] M. Reyes-Sierra, C.A. Coello Coello, "Multi-Objective Particle Swarm Optimizers: A Survey of the State-of-the-Art", International Journal of Computational Intelligence Research, Vol. 2, No. 3, pp. 287-308, 2006.

[22] A. Babarit, "Hydrodynamic optimisation and optimal control of a Wave Energy Control" (in French: "Optimisation hydrodynamique et contrôle optimal d'un récupérateur de l'énergie des vagues"), $\mathrm{Ph} . \mathrm{D}$. thesis, Ecole Centrale de Nantes, 2005.

[23] M. Ruellan, "Sizing methodology of a wave energy converter" (in French "Méthodologie de dimensionnement d'un système de récupération de l'énergie des vagues"), Ph.D. thesis, Ecole Normale Supérieure de Cachan, 2007.

\section{BIOGRAPHIES}

Judicaël Aubry was born in Nantes, France, on 1985. He received the B.Sc. degree in electrical engineering from the Ecole Normale Supérieure de Cachan (ENS de Cachan), Cachan, France, in 2005, and the M.Sc degree in electronic systems and electrical engineering from the Ecole Polytechnique de l'Université de Nantes, Nantes, France, in 2008. He is currently working toward the Ph.D. degree in electrical engineering at the Laboratoire Systèmes et Applications des Technologies de l'Information et de l'Energie (SATIE), ENS Cachan Bretagne, Centre National de la Recherche Scientifique (CNRS), Université Européenne de Bretagne (UEB), Bruz, France. His current research interests include wave energy conversion, electrical drive optimization, particle swarm optimization and energy storage.

Hamid Ben Ahmed received the PhD degree and HDR degree in 1994, and 2006 respectively. From 1994 to 1997, he was a Research Associate in the SATIE laboratory. Since 1997, he was an Assistant Professor in the Mecatronique Department of "Ecole Normale Supérieure de Cachan," Brittany Branch, France. His research interest include the design, modelling and optimisation of novel topologies of electromagnetic actuators and generators, and the optimisation of renewable energy systems.

Bernard Multon was born on 1960. He received the M.S. degree in electrical engineering from the Ecole Normale Superieure de Cachan, Cachan, France, in 1981, Electrical Engineering Agrégation in 1982 and the Ph.D. degree from the University of Paris 6, Paris, France, in 1985. From 1988 and 1995, he was Assistant Professor in the Electrical Engineering Department, Ecole Normale Supérieure de Cachan (ENS de Cachan), and Leader of the Research Special Actuator Design Group in LESiR-CNRS. Since 1995, he is Full Professor in the Brittany Site of ENS de Cachan (Ker Lann Campus in south ofRennes). He teaches in the Mechatronics Department and he conducts his research in SETE team of laboratory SATIE-CNRS on electromechanical chain sizing and new electrical energy conversion systems (renewable and human power). 